\title{
Os fundos de pensão como agentes da produção do espaço: um olhar a partir da literatura internacional.
}

Les fonds de pension en tant qu'agents de la production de l'espace: un regarde de la littérature internationale.

Los fondos de pensiones como agentes en la producción del espacio: una mirada desde la literatura internacional.

Pension funds as agents of space production: a look into the international literature.

\section{Maira Magnani Asencio}

\section{(2) OpenEdition}

Journals

Edição electrónica

URL: http://journals.openedition.org/espacoeconomia/6004

DOI: 10.4000/espacoeconomia.6004

ISSN: 2317-7837

Editora

Núcleo de Pesquisa Espaço \& Economia

Refêrencia eletrónica

Maira Magnani Asencio , « Os fundos de pensão como agentes da produção do espaço: um olhar a partir da literatura internacional. », Espaço e Economia [Online], 14 | 2019, posto online no dia 12 agosto 2019, consultado o 06 setembro 2019. URL : http://journals.openedition.org/ espacoeconomia/6004; DOI : 10.4000/espacoeconomia.6004

Este documento foi criado de forma automática no dia 6 Setembro 2019

(C) NUPEE 


\title{
Os fundos de pensão como agentes da produção do espaço: um olhar a partir da literatura internacional.
}

\author{
Les fonds de pension en tant qu'agents de la production de l'espace: un regarde \\ de la littérature internationale. \\ Los fondos de pensiones como agentes en la producción del espacio: una mirada \\ desde la literatura internacional. \\ Pension funds as agents of space production: a look into the international \\ literature.
}

Maira Magnani Asencio

\section{Introdução}

1 A ação dos agentes do mercado imobiliário é amplamente responsável pelo modo como o meio ambiente urbano construído se desenvolve e evolui (THEURILLAT et al., 2010). Nos últimos anos, os fundos de pensão entraram em cena como figuras centrais no setor imobiliário (VAN LOON \& AALBERS, 2017) - para o caso brasileiro, "o tamanho de seu patrimônio e a velocidade do crescimento são o maior indício da importância que os fundos assumem na economia brasileira." (FIX, 2007). Atualmente, os dados disponibilizados pela Revista de Fundos de Pensão, da ABRAPP, mostram que essas entidades já possuem mais de 790 bilhões de reais alocados em diferentes tipos de ativos, o que resulta em aproximadamente $12,8 \%$ do PIB brasileiro. No que concerne a sua participação no mercado imobiliário:

(...)os fundos de pensão tem um patrimônio significativo no Brasil se comparados à capacidade de investimento de outros agentes. Além disso, sua participação no setor imobiliário foi muito grande em ambos os sentidos: na importância que os imóveis assumiram na composição do portfólio dos fundos, e na importância que os recursos investidos pelos fundos tiveram para o o setor imobiliário. (FIX, 2007). 
2 Esse trabalho tem por objetivo discutir o papel dos fundos de pensão na produção do espaço urbano através de uma análise da sua atuação no mercado imobiliário comercial. Para tanto, realiza-se um esforço de reunir um quadro bibliográfico base que discute os canais utilizados pelos fundos de pensão para investir no mercado imobiliário e se examina o que a literatura internacional recente tem apontado com relação às novas práticas profissionais de gestão imobiliária adotadas e os impactos que essas geram na gestão do portfólio imobiliário dos fundos de pensão e na produção do espaço urbano.

3 O presente artigo circunscreve-se em uma ampla discussão a respeito do fenômeno da financeirização da economia e do espaço urbano. Chama-se de "financeirização" as mudanças ocorridas após o esgotamento do modelo de regulação do sistema monetário internacional pactuado em Bretton Woods, combinada à tendência de reestruturação dos Estados-nação e à guinada neoliberal da economia ocorrida no pós década de 70. "Apesar da importância da financeirização, não há nenhum consenso sobre sua definição" (AOYAMA et al., 2010). Segundo Klink \& Barcellos (2017), são três as principais correntes que analisam a financeirização e conceituam esse fenômeno: 1) a corrente marxista, que compreende as mudanças institucionais e macroeconômicas ocorridas com o advento da financeirização, que os autores denominam de "abordagem da economia política"; 2) a corrente que tem como tradição as discussões sobre governança corporativa, designada de "contabilidade crítica" e; 3) a vertente que analisa como a financeirização afetou e penetrou na vida cotidiana, que os autores denominam de "financeirização da vida cotidiana".

4 Para facilitar o prosseguimento dos objetivos propostos nesse trabalho, partiremos de duas definições amplas que mostram a abrangência do processo de financeirização e que reforçam a ligação intrínseca entre esse fenômeno e o campo do planejamento urbanometropolitano. Manuel Aalbers, um dos teóricos contemporâneos que mais contribuem para a discussão sobre o tema, propõe a seguinte definição para financeirização:

A crescente dominância de agentes, mercados, práticas, métricas e narrativas financeiros, nas múltiplas escalas, o que tem gerado uma transformação estrutural das economias, das corporações (incluindo instituições financeiras) dos Estados e das famílias. (AALBERS, 2015 apud KLINK \& BARCELLOS DE SOUZA, 2017)

5 Essa conceitualização se mostra interessante pois reforça a ideia de que esse fenômeno atingiu diferentes tipos de instituições e atores, desde o Estado, o mercado financeiro, até famílias e o próprio individuo. A análise que se propôs desenvolver nesse trabalho discutirá as alterações encontradas nos fundos de pensão, tendo como premissa que esses agentes institucionais transformaram sua formação, atuação e tomada de decisão, na medida em que também foram expostos a essa crescente dominância financeira.

6 Valeremo-nos também das contribuições de David Harvey que, segundo French et al. (2011), entende a financeirização como um processo que ao mesmo tempo foi influenciado e influencia as relações sociais e a construção do espaço urbano. Para o geógrafo a financeirização:

(...) deve ao menos ser entendida como um fenômeno profundamente espacial, porque estabelece a promessa de uma solução para a crise do capitalismo angloamericano contemporâneo baseada numa solução financeira-espacial. (HARVEY, 1982, 1989, 2010 apud FRENCH et al., 2011).

7 Os trabalhos desse autor, que basearam grande parte da produção acadêmica do ramo do planejamento urbano, sugerem que a terra tem assumido papel de ativo financeiro e, portanto, como ativo financeiro, a terra e seus produtos, como a habitação, passaram a 
ser vistos sob uma lógica mercantilizada, o que altera a relação do Estado, na provisão de políticas públicas, e dos demais agentes envolvidos nesse processo (RUFINO, 2017).

8 A literatura recente dedicada à produção do espaço e espoliação imobiliária no mundo contemporâneo retrata o encontro das esferas financeira e imobiliária a partir de diversas maneiras, tais quais: da criação de ativos que circulam no mercado financeiro e que encontram como "lastro" a terra e a produção imobiliária (RUFINO, 2017; VAN LOON \& AALBERS, 2017; PEREIRA, 2017); do surgimento de novas engenharias financeiras que alteram consideravelmente as corporações modernas e a forma de se enxergar o lucro (RIECHE, 2005; JARDIM, 2011; CLARK, 1998a, 2000; HALEY \& BARRETT, 1990); da alteração na forma de produção e financiamento da habitação e bens públicos e da provisão de políticas públicas em geral (ROLNIK, 2015; FIX, 2007); do envolvimento de diferentes agentes (públicos e privados) que influenciam na construção de normas e que participam de convenções (MARQUES, 2016; SANFELICI \& HALBERT, 2018; HALBERT \& ATTUYER, 2016).

9 São muitos os ativos que circulam no mercado financeiro e que encontram como "lastro" a terra e a produção imobiliária. Com a promessa de trazer liquidez e agilidade a um setor que possui especificidades que dificultavam o acesso de pequenos investidores, essa classe de ativos foi criada, regulamentada pelo Estado e se apresenta hoje uma possível opção de investimento. Esses papéis financeiros nada mais são do que uma forma de capital fictício e, por não representar valor até serem transformado em um real investimento, representam certos riscos associado com sua taxa de retorno. Para minimizar esses riscos, uma estratégia seguida por investidores profissionais (chamados de "gestores de fundos") tem sido a de diversificar o portfólio para garantir investimentos seguros, mas com altas taxas de retorno.

10 A lógica financeira sobre o meio imobiliário se reverbera, também, na medida em que os detentores de capital criam "medidas" que permitem uma comparação dos produtos imobiliários não pela sua localização, especificidades técnicas e suas características em geral, mas sim, através de uma dado quantitativo padrão que passa a ser usado para diferenciá-los e hierarquizá-los. (THEURILAT et al., 2010). Essas novas engenharias financeiras, portanto, "possibilitam projetos, atores e espaços a serem comparados, fazendo com que a relação entre os detentores do capital e os reais investidores fique distante e opaca" (THEURILLAT et al., 2010). Van Loon e Aalbers (2017) argumentam que os atores do mercado financeiro, através da criação de novas engenharias financeiras, transformaram o mercado imobiliário, a classe de investimento que mais necessita ser fixada espacialmente devido à sua indivisibilidade, imobilidade, iliquidez e projeto de um investimento de longo prazo, em instrumentos financeiros que são comparáveis a qualquer outra classe de segmentos de ativos.

11 Os fundos de pensão, que funcionam através de um regime de previdência por capitalização, tornaram-se na década de 80 e 90 grandes atores do mercado financeiro, transformando a amplitude, a estrutura e o funcionamento desses mercados. A financeirização, por assim dizer, alterou a forma como os investidores institucionais realizam a gestão do seu patrimônio e também a forma como medem e enxergam resultados e metas (SAUVIAT, 2005). A literatura recente, que será melhor explorada nas seções seguintes, aponta que essas mudanças na racionalidade dos fundos de pensão resultaram em estratégias de investimento diferenciadas, alterando a gestão do portfólio imobiliário e, consequentemente, gerando diferentes impactos no ambiente urbano construído. 
12 Na tentativa de sistematizar uma discussão bibliográfica internacional acerca da temática, o presente artigo será divido da seguinte forma: o primeiro capitulo tratará dos impactos trazidos pela financeirização no ambiente e na atuação dos fundos de pensão; o segundo discutirá as mudanças das estratégias de investimento e na racionalidade dos fundos de pensão no que diz respeito à gestão do portfólio imobiliário; e o terceiro reunirá os resultados e impactos estudados internacionalmente das estratégias de investimento dos investidores institucionais nas cidades.

\section{Os fundos de pensão como agentes do capital financeiro}

13 Clark (1998) denomina o capitalismo pós década de 80 de "Capitalismo de Fundos de Pensão" - "capitalismo de fundo de pensão é um estágio adicional na evolução do capitalismo, em vez de uma ruptura profunda com o passado" (Clark, 1998). Segundo o autor, os fundos de pensão surgem como importantes agentes do capital financeiro, sendo que sua expressividade pode ser analisada de duas formas: pelas extraordinárias taxas de crescimento de seus ativos e reservas e pelo seu poder como agente político, envolvido na manipulação da governança corporativa das empresas e das políticas desenvolvidas pelo Estado. Os fundos de pensão são uma força a ser considerada quando o governo procura administrar as taxas de juros e as taxas de câmbio, sendo que suas vozes são cada vez mais poderosas na manutenção de práticas de governança corporativa nas empresas e nas políticas públicas do país (Clark, 1998). Na mesma linha de argumentação, Grun (2003) admite que os fundos de pensão assumiram um protagonismo muito grande na cena econômica brasileira e que são "instituições importantes na 'governança' do capitalismo contemporâneo" (p. 9).

14 No mundo, as taxas de crescimentos dos ativos e reservas dos fundos são expressivas: no Reino Unido, desde a década de 80 , os ativos individuais de pensão e aposentadoria aumentaram cerca de 12 vezes, chegando na casa de $€$ 1,5 trilhão; nos Estados Unidos, de 1980 a 1997, os ativos cresceram cerca de dez vezes mais, chegando a somar mais de US\$ 7 trilhões (CLARK, 2000). Para Clark (2000) o crescimento dos ativos dos fundos de pensão nos últimos trinta anos foi o responsável pela vitalidade dos mercados financeiros anglosaxãos.

15 A literatura sobre "Capitalismo dos fundos de pensão" oferece detalhes sobre como a financeirização permitiu aos fundos de pensão desenvolverem estratégias de investimento mais arrojadas, o que foi amplamente responsável pelo rápido crescimento de seus portfólios e ativos (CLARK, 2000; CORPOTAUX et al., 2009; VAN LOON \& AALBERS, 2017; SAUVIAT, 2005; THEURILLAT et al, 2010). Essa transformação "ilustra como os investidores institucionais deslocaram seus investimentos do setor econômico 'real', onde 'os retornos e os riscos são entendidos em relação aos espaços e tempos que são particulares aos ciclos economicos e de produção' para 'a esfera financeirizada da economia, onde a dicotomia risco-retorno corresponde a um exercício de engenharia financeira"'(CORPATAUX et al., 2009 apud VAN LOON \& AALBERS, 2017).

16 Segundo Sauviat (2005), a política adotada por esses agentes na aplicação desses recursos orientou-se em direção a ativos cada vez mais arriscados, como açōes, mas também passou por uma intensa diversificação de portfólio de investimento, prezando a garantia de liquidez e ganhos financeiros em diferentes mercados de ativos. O modelo "Modern 
Portfolio Theory" (MARKOWITZ, 1952 apud VAN LOON \& AALBERS, 2017) passa a ser fundamental para a maioria dos fundos de pensão estudados pela literatura - nesse, a criação de métricas e números padronizados, fáceis de ser comparados entre si, mesmo quando referente a classe de ativos muito distintas, facilita a construção de um portfólio diverso que traz uma performance alta e com baixos riscos (CLARK, 2000; CORPOTAUX et al., 2009 apud VAN LOON \& AALBERS, 2017). A financeirização, conforme aponta a literatura, também impactou a forma de se realizar gestão dos investimentos dos fundos de pensão - há uma intensa terceirização, ou seja, esses atores alocam parte de suas reservas de dinheiro para empresas terceiras (geralmente bancos ou administradoras de fundos de investimentos) que assumem os riscos iminentes da aplicação desses recursos de acordo com a natureza do regime (de benefícios ou de contribuições definidas) (SAUVIAT, 2005; CORPOTAUX et al., 2009; VAN LOON \& AALBERS, 2017).

17 De maneira esperada, para absorver esse fluxo de capital institucional, novas classes de ativos foram criadas usando diferentes tipos de "matérias-primas", como hipotecas, empréstimos, infraestrutura e mercado imobiliário, sendo este último o mais alternativo dos investimentos (VAN LOON \& AALBERS, 2017). Apesar da diversificação do portfólio, seguindo o modelo de "Modern Portfolio Theory", garantir em tese uma diferenciação que dirime quase que completamente os riscos associados aos investimentos, "A transformação de investimentos altamente relacionados com contextos geográficos e econômicos complexos em ativos financeiros não faz com que riscos reais desapareçam" (AALBERS, 2012; PANI \& HOLMAN, 2014 apud VAN LOON \& AALBERS, 2017).

\section{Retrato da literatura internacional sobre a atuação dos fundos de pensão no mercado imobiliário}

19 Theurillat et al. (2010) realizaram um estudo aprofundado sobre o caso dos fundos de pensão suíços entre os anos de 1992 e 2004, nos quais cerca de 15\% do total dos investimentos dos fundos de pensão da época eram destinado ao setor imobiliário. Esse estudo investigou como a ação dos fundos de pensão suíços se alterou com o advento da financeirização e quais os impactos que essa provocou na forma com que esses agentes realizam operações no mercado imobiliário comercial. Conforme mostram os autores, são duas as formas possíveis dos fundos de pensão investirem no setor imobiliário: de maneira direta e/ou de maneira indireta.

20 Altaprima \& Ernst \& Young (2004, p.18 apud THEURILLAT et al, 2010) ressaltam um aspecto interessante sobre a diferença das estratégias de investimentos dos fundos de pensão, se comparados com as estratégias de outros investidores institucionais. Tradicionalmente, os fundos de pensão adotam uma visão patrimonialista sobre seu imóvel, ou seja, uma vez construídos ou comprados, eles permanecem donos desses imóveis por um longo período, sendo muito rara a cessão ou a venda. Esse comportamento está estritamente relacionado com o canal direito de investimento em imóveis, segundo Theurillat et al. (2010).

21 O canal direto de investimento é aquele no qual os fundos de pensão realizam a compra direta do imóvel, recebendo os direitos de propriedade e tendo que arcar com total responsabilidade operacional do ativo. Esse canal requer uma política de investimentos e gestão próprias, que podem ser executadas tanto por uma equipe interna, utilizando os 
conhecimentos próprios de seus funcionários, como por uma equipe terceira, que pode facilitar algumas fases da gestão do imóvel adquirido. Esse tipo de canal, portanto, requisita aos fundos de pensão certo tipo de expertise para lidar com o mercado imobiliário, exigindo corpo técnico especializado tanto em aspectos técnicos do investimento imobiliário (arquitetos, planejadores urbanos e etc.) como também, pessoal familiarizado com os aspectos legais e financeiros ligados a esse tipo de investimento (advogados, economistas, administradores e etc.) Certamente, como os próprios autores apontam, esse corpo técnico "in-house" depende profundamente do tamanho do fundo e da importância que o portfólio imobiliário tem para o mesmo (THEURILLAT et al, 2010).

22 Por tratar-se de um investimento que necessita de certa assertividade, para que a taxa de ocupação do imóvel seja alcançada e gere retornos financeiros em sintonia com as metas atuariais, na realidade, o que ocorre com a maioria dos fundos é que quando se faz necessária uma expertise diferenciada (como operadores de portfólio, desenvolvedores de projetos e empreendimentos ou especialistas em certificados financeiros e contabilidade) a maioria deles recorre a especialistas externos, como consultorias e bancos de investimento (ALTAPRIMA \& ERNST \& YOUNG, 2004, p. 44 apud THEURILLAT et al, 2010).

23 Para o caso de investimentos imobiliários utilizando o canal direto, a gestão delegada concerne, comumente, somente a última das quatro etapas que envolvem a gestão de portfólio imobiliário. Segundo o modelo proposto por Van Loon \& Aalbers (2017), são quatro as etapas principais: a gestão do fundo, na qual são feitas as principais decisões estratégicas do tipo de investimento que será feito pelo fundo; a gestão do portfólio, que envolve qual segmento do imobiliário aplicar os recursos (residencial, hoteleiro, comercial e etc.); a gestão dos ativos, na qual realiza-se a compra e venda de ativos na linha do que foi decidido estrategicamente também); e a gestão da propriedade imobiliária, na qual os fundos, como donos da propriedade, devem administrá-la e mantêla.

24 Por sua vez, o canal indireto de investimento, também chamado de canal financeirizado, é aquele no qual os fundos de pensão participam do mercado imobiliário através da compra (ou da participação) em diferentes veículos financeirizados que possuem como lastro o imóvel ou a terra. Como resultado, os fundos de pensão viram somente investidores. A gestão do investimento e do patrimônio passa a ser feita por entidades especializadas que possuem competências técnicas consideradas mais atuais e efetivas essa estratégia sustenta-se no entendimento de que a gestão da propriedade imobiliária dos fundos de pensão necessita de um olhar mais atento ao cenário econômico, ou seja, que o ativo imobiliário necessita de uma política mais ativa de "buy and manage" (comprar e gerir) (CORPOTAUX et al., 2009; THEURILLAT et al., 2010; VAN LOON \& AALBERS, 2017).

25 É importante ressaltar que o grau de delegação depende estritamente dos marcos regulatórios e legais aos quais os fundos respondem - no caso suíço, estudado por Theurillat et al. (2010), por exemplo, a lei permite que outras instituições, como fundos imobiliários e companhias imobiliárias, realizem a gestão do portfólio, a gestão dos ativos imobiliários e a gestão da propriedade imobiliária. Nesse caso, somente a decisão estratégica de gestão do fundo sobre o quanto investir e se investir no mercado imobiliário passa pelos fundos de pensão, incumbindo a um terceiro as decisões referentes ao investimento imobiliário, como por exemplo quais segmentos investir (residencial, comercial, e entre outros), em qual região, e etc. Desta forma, “ 'bolsões' de investimento parecem depender das ações e desejos dos agentes financeiros, que parecem 
desempenhar um papel central na maneira como as áreas são selecionadas." (THEURILLAT et al, 2010).

26 De maneira semelhante ao entendimento de Theurrilat et al (2010), Van Loon \& Aalbers (2017), ao analisar o caso dos fundos de pensão holandeses, entendem que a financeirização assumiu um papel decisivo na mudança de prática e ideologia das corporações, ficando os investidores institucionais também sujeitos a essa nova forma de se medir e enxergar lucros associados a produção imobiliária.

27 A partir da análise de um período pré-financeirização (anos 80) e um período pósfinanceirização (a partir de 2010) dos fundos de pensão holandeses, os autores descrevem alterações observadas nas quatro etapas de gestão anteriormente mencionadas: no período pré-financeirização, a gestão do fundo tinha como estratégia o alcance de objetivos políticos e sociais em sua aplicação de recursos, enquanto que no período pósfinanceirização a estratégia estava mais focada nas taxas de risco e retorno dos investimentos imobiliários.

28 Com relação à gestão do portfólio, em momento anterior à financeirização os fundos holandeses investiam em classes restritas de ativos imobiliários, majoritariamente nacionais, enquanto que depois da financeirização, seu portfólio passou a ser mais variado, incluindo investimentos em ativos imobiliários de outros países. A gestão de ativos, por sua vez, entendia o mercado imobiliário como algo intangível e difícil de definir ganhos sobre rendas futuras, já no período posterior, as medidas qualitativas trazidas pela financeirização permitiram que o setor realizasse um investimento em imóvel baseado no valor futuro e fictício daquele imóvel. A gestão de propriedade apresentou no primeiro período analisado uma orientação mais emocional com a propriedade adquirida, enquanto que no período posterior o imóvel é somente considerado um "ativo qualquer" sobre o qual o investidor não possui conhecimento e interesse em geri-lo. (VAN LOON \& AALBERS, 2017)

\section{Resultados empíricos da atuação dos fundos de pensão internacionais no mercado imobiliário local.}

Conforme observa Van Loon \& Aalbers (2017), Henneberry \& Roberts (2008) concluíram que a única pesquisa que de fato mostrou como e por que as estratégias financeirizadas de investimento no mercado imobiliário feitas pelos investidores institucionais produzem determinados efeitos na cidade foi a desenvolvida nos casos dos fundos de pensão suíços. Ao investigar os diferentes tipos de destinos que o capital dos fundos de pensão pode assumir no que tange aos investimentos imobiliários, Theurillat et al. (2010) concluem que as instituições nas quais os canais de investimentos indiretos eram feitos estavam agindo de maneira muito semelhante ao modo como os fundos de pensão geriam e investiam sua própria carteira de imóveis, adquirida pelo canal direto de investimento: ambos se concentravam nas áreas urbanas do país e resultavam em imóveis de alto padrão.

31 A presente seção reúne os resultados obtidos por Theurillat et al. (2010) ao estudar as estratégias de investimento no mercado imobiliário adotadas pelos fundos de pensão suíços nos anos de 1992 a 2004. Vale ressaltar que os autores utilizaram uma metodologia mista composta por analise de dados de investimentos e entrevistas semi-estruturadas (realizadas em dois períodos) com atores envolvidos na gestão de portfólio imobiliário. 
32 Segundo os autores, o total de investimentos em propriedade imobiliária realizado pelos fundos de pensão suíços passou de 17\% em 1992 para 14\% em 2004, sendo que 78\% desses investimentos continuam sendo feitos pelo canal tradicional de investimento. Apesar do canal direito ainda ser o mais utilizado, foi observado um aumento significativo no método de investimento indireto no período estudado - passou de 5\% em 1992 para 22\% em 2004.

33 Com relação ao padrão espacial dos investimentos diretos, $60 \%$ dos gestores dos fundos reportaram que suas propriedades adquiridas eram próximas da empresa patrocinadora do fundo e que assim continuariam sendo. Somente $13 \%$ disse que seus investimentos poderiam ser feitos em áreas diferentes de onde o empregador estivesse e para terceiros utilizar. A proximidade espacial dos investimentos diretos do fundo de pensão com a sede da empresa tem sido considerada importante pelos gestores dos fundos - das companhias estudadas por Theurillat et al. (2010) grande parte possui imóveis localizados onde a companhia teve sede em algum período de sua história. A explicação obtida pelos pesquisadores gira em torno de três principais causas: 1) os gestores não consideram racional comprar um imóvel por vias diretas que não seja para uso de seus empregados e empregadores; 2) os gestores consideram importante conhecer o mercado local de propriedades, assim como as regulações, por isso, estar próximo da sede é visto como essencial; e 3) os fundos de pensão estatais, comumente grandes e tradicionalmente investidores utilizando do canal direto, são objetos de controles políticos e sofrem grande influência dos trabalhadores que contribuem para o sistema de aposentadoria. Segundo as entrevistas realizadas, a grande participação dos trabalhadores da empresa patrocinadora na tomada de decisão dos fundos é um fator fundamental para compreender a compra de imóveis próximos ao local de trabalho.

34 De maneira intuitiva, foi descoberto que a distribuição por segmentos dos investimentos diretos, usando como amostra os 5 maiores fundos de pensão que detêm 822 empreendimentos, é majoritariamente residencial. De maneira semelhante, a diversificação entre segmentos imobiliários envolvendo os investimentos indiretos é igualmente restrita, o que se deve à oferta de produtos alternativos pelas gestoras de portfólio imobiliário e pelos fundos de imobiliários. Como mostrou a pesquisa, essas entidades terceiras oferecem produtos financeiros que são quase que completamente centrados nos segmentos residenciais e comerciais.

35 Com relação à diversificação geográfica, o canal indireto também não mostrou grandes diferenciações se comparado com o canal direto, na contramão do que a estratégia de gestão de portfólio mais ativa (buy and manage) supostamente traria. Segundo o estudo de Theurillat et al. (2010), a diversificação espacial está limitada somente a certas áreas urbanas, especificamente metropolitanas.

Disso, apesar do grau de especialização de produtos de investimento (em termos da cisão entre propriedade residencial e comercial), veículos de investimento coletivos têm uma visão geográfica focada em áreas urbanas, particularmente nas maiores áreas urbanas. Assim, há um foco principalmente em áreas reconhecidas como centros de atividade, fazendo com que sigam uma visão hierarquizada das áreas urbanas. Fora dessas áreas, o investimento é quase não existente. (THEURILLAT et al., 2010)

36 No que concerne à gestão delegada, três quartos das instituições fazem uso de especialistas externos como parte das suas próprias políticas de investimento em propriedade imobiliária. Neste caso estudado, a participação de terceiros gera pouca 
influência nos padrões de escolhas feitos pelos gestores dos fundos, já que é mobilizado uma expertise que não tange à "estratégia" investimento.

No caso do investimento utilizando o canal indireto/financeiro, notou-se que os especialistas de instituições terceiras suíças baseiam seus julgamentos nas especificidades e localização do empreendimento, critério muito semelhante ao utilizado pela própria entidade de previdência. Com essa constatação, os autores concluem que o canal indireto não consegue transcender os mercados imobiliários compartimentalizados (com características regionais e locais bem demarcadas e baseado em um "acordo mútuo" entre os agentes envolvidos), ou seja, os investidores não conseguem ser independentes das circunstâncias locais específicas e não conseguem, por assim dizer, realizar uma gestão de investimentos imobiliários com maior liquidez e maior diversificação.

Desta forma, dadas as dificuldades de lidar com o mercado imobiliário, instituições coletivas (bancos, consultorias, fundos de investimentos e etc.) se comportaram, no período estudado, da mesma forma que os fundos de pensão no que concerne a sua ação como investidores e gestores no mercado imobiliário: ambos têm mostrado um comportamento "buy and hold" quando realizam investimentos. Além disso, essas instituições, da mesma maneira que os fundos de pensão, investem majoritariamente em imóveis ja construídos, o que pode ser responsável, na visão dos autores, pela recente inflação nos preços dos imóveis residenciais na Suíça.

39 Em resumo, Theurillat et al. (2010) demonstram que a via de canal indireto, que pode ocorrer, no caso suíço, tanto através da compra de veículos financeiros como na compra de ações de empresas do ramo imobiliário, não trouxe para os fundos de pensão a famigerada possibilidade de tornar seu portfólio mais diversificado e, portanto, minimizar os riscos. Na primeira possibilidade, a restrição do mercado financeiro suíço é um limitador, e na segunda, a possibilidade de ter o portfólio imobiliário gerido por especialistas financeiros é compensada pela falta de liquidez do mercado de imóveis suíço (THEURILlAT et al., 2010). Isso explica, na visão dos autores, porque somente $22 \%$ do investimento realizado por fundos de pensão suíços seja feita pelo canal indireto.

\section{Conclusão}

40 A hipótese que sustentavam Theurillat et al. (2010) era de que os canais distintos de investimento no mercado imobiliário realizado pelos fundos de pensão suíços resultariam em diferentes impactos no ambiente urbano construído. A preferência pelo canal indireto de investimento, em um cenário de uma economia financeirizada que objetiva atender as expectativas do capital financeiro, favoreceria certos tipos de espaço, certos tipos de atores e certos tipos de investimentos no mercado imobiliário. Contudo, através de uma análise empírica e com teor metodológico assertivo, concluiu-se que a única exceção notável entre os intermediários financeiros (responsáveis pelo investimento indireto) e os fundos de pensão (responsáveis pelo canal direto) era de que os primeiros concentravam seus investimentos nas principais áreas urbanas do país, preferencialmente àquelas próximas dos atores financeiros, e os segundos concentravam seus investimentos em áreas (também urbanas) próximas as sedes da entidade previdenciária.

41 O que se coloca em questão é se a razão pela qual somente $22 \%$ dos investimentos conduzidos pelos fundos de pensão serem realizado pelo canal indireto deve-se: 1) à persistência de uma racionalidade que preza a condução de um investimento em 
imobiliário carregado de valor simbólico, que atinja objetivos políticos e sociais; 2) a limitação do mercado financeiro de trazer liquidez e diversificação no que tange aos investimentos no mercado imobiliário ou; 3) a limitação do próprio setor imobiliário em absorver o capital institucional, seja por restrições legais, espaciais ou pela formação de redes baseadas em acordos.

Seja qual, ou quais forem, as razões em determinado contexto geográfico, a via de investimento indireto tem se tornado uma opção e, em alguns contextos, como no caso brasileiro, a única opção. A literatura internacional aponta para o sentido de que, apesar dos resultados dos investimentos no ambiente urbano através dos dois canais não se mostrarem significativamente diferentes, a própria adoção de práticas de gestão de portfólio orientadas, por exemplo, pelo modelo de "Modern Portfolio Theory", alterou a forma como os investidores institucionais enxergam e aplicam no setor imobiliário (VAN LOON \& AALBERS, 2017). O investimento em imobiliário, considerado "opaco" e de difícil mensuração em termos quantitativos, passou a ser cada vez mais transparente, descrito sob a forma de instrumentos quantitativos comparáveis a qualquer outro investimento.

(...) investidores estão, agora, comprando propriedades pelas suas características financeiras ao invés do seu potencial no interior da malha urbana, desse modo acabam simulando/enganando os benchmarks, concentrando investimentos em localizações selecionadas e criando um efeito manada (HENNEBERRY \& ROBERTS, 2008; LIZIERI \& PAIN, 2014 apud VAN LOON \& AALBERS, 2017)

Fica claro, portanto, que apesar de haver limites para a financeirização quando se trata da atuação dos fundos de pensão no mercado imobiliário, o momento pós década de 80 alterou profundamente a forma como esses atores enxergam a categoria de investimento imobiliário. Ademais, os impactos no ambiente urbano construído podem não ser, como mostrou o caso suíço, significativamente diferentes quando se observa os canais de investimento utilizado, contudo, é notável que esses investimentos continuam, seja qual for o canal utilizado, seguindo um padrão seletivo e que reverbera desigualdades - "a marcada seletividade espacial adotada pelos investidores institucionais contribui para a dinâmica das concentrações econômicas contemporâneas observadas em cidades e regiões." (HALBERT, 2010 apud HALBERT et al., 2014) - o que se entende ser motivo suficiente para compreender as mudanças que atingem o setor e os impactos trazidos pelos investimentos institucionais em diferentes contextos geográficos.

\section{BIBLIOGRAFIA}

AOYAMA, Y.; MURPHY, J., T.; HANSON, S. Key Concepts in Economic Geography. Sage Publications Ltd. 2010.

CLARK, G. L. Pension fund capitalism: a casual analysis. Geografiska Annaler, 80b, p. 139 - 157, 1998.

CLARK, G. L. Pension systems: a comparative perspective. Mainsfield Rc., Oxford, 2000.

FIX, M. São Paulo cidade global: fundamentos financeiros de uma miragem. São Paulo: Boitempo, 2007. 
FRENCH, S.; LEYSHON, A.; WAINWRIGHT, T. Financializing space, spacing financialization. Progress in Human Geography, p. 798 - 819, 2011.

HALBERT, L.; ATTUYER, K. Introduction: The financialisation of urban production: Conditions, mediations and transformations. Urban Studies, 1- 15, 2016.

HALBERT, L.; HENNEBERRY, J.; MOUZAKIS, F. The financialisation of business property and what it means for cities and regions. Regional Studies, 48:3, 547-550, 2014.

HEALEY, P.; BARRETT, S. M. Structure and agency in land and property development processes: some ideas for research. Urban Studies, 1990.

JARDIM, M. A. C. A Natureza social das finanças: fundos de pensão, sindicalistas e recomposição das elites. Maria Chaves Jardim (Org.) - Bauru, SP: Edusc, 2011.

KLINK, J.; BARCELLOS DE SOUZA, M. Financeirização: conceitos, experiências e a relevância para o campo do planejamento urbano brasileiro. Sao Paulo: Caderno Metrópole, v.19, n. 39, p. 379 - 406, 2017.

MARQUES, E. De volta aos capitais para melhor entender as políticas urbanas. São Paulo: Novos Estudos CEBRAP, Edição 105, Volume 35, N. 2, Julho de 2016.

PEREIRA, P. C. X. Preço e valor na financeirização da produção do espaço. In: In: O espaço e a metropolização: cotidiano e ação | Organizadores: Alvaro Pereira, João Rua e Regina Célia de Mattos. Rio de Janeiro: Consequência Editora, 2017.

RIECHE, F. C. Gestão de riscos em fundos de pensão no Brasil: situação atual da legislação e perspectivas. Rio de Janeiro: Revista do BNDES, v. 12, n. 23, p. 219 - 242, 2005.

ROLNIK, R. Guerra dos lugares: a colonização da terra e da moradia na era das finanças. São Paulo: Boitempo, 2015

RUFINO, M. B. C. Financeirização do imobiliário e transformações na produção do espaço. In: 0 espaço e a metropolização: cotidiano e ação | Organizadores: Alvaro Pereira, Joao Rua e Regina Célia de Mattos. Rio de Janeiro: Consequência Editora, 2017.

SANFELICI, D.; HALBERT, L. Financial market actors as urban policy-makers: the case of real estate investment trusts in Brazil. Urban Geography, V. 40:1, p. 83-103, Disponível em: DOI: $\underline{10.1080 / 02723638.2018 .1500246}$, acessado em 21 de junho de 2019, 2018.

SAUVIAT, C. Os fundos de pensão e os fundos mútuos: principais atores da finança mundializada e do novo poder acionário. In: CHESNAIS, F (Org.). A finança mundializada: raízes sociais e politicas, configuração, consequências. Tradução de Rosa Maria Marques e Paulo Nakatani. Sao Paulo: Boitempo Editorial, 2005.

THEURILLAT, T.; CORPATAUX, J.; CREVOISIER, O. Property Sector Financialization: The Case of Swiss Pension Funds (1992 - 2005). Publicado em European Planning Studies 18, 2º volume, p. 189 $-212,2010$.

VAN LOON, J.; AALBERS, M. B. How real estate became 'just another asset class': the financialization of the investment strategies of Dutch institucional investors. European Planning Studies, 25:2, p. 221-240, Jan 2017.

\section{RESUMOS}

Os fundos de pensão figuram-se como importantes agentes nas economias mundiais. A financeirização alterou a forma como os investidores institucionais realizam a gestão do seu 
patrimônio e também a forma como medem e enxergam resultados e metas (SAUVIAT, 2005). A literatura recente aponta que essas mudanças na racionalidade dos fundos de pensão resultaram em estratégias de investimento diferenciadas, inclusive no que concerne ao investimento em imobiliário. Como apontam Van Loon \& Aalbers (2017), atualmente, há pouco conhecimento produzido acerca de como os objetivos financeiros vieram a dominar e modificar as estratégias de investimento dos investidores institucionais e como isso afeta o espaço urbano construído - na realidade, a única pesquisa que de fato mostrou como e por que essas estratégias produzem determinados efeitos na cidade, foi a desenvolvida por Theurillat et al. (2010) para o caso dos fundos de pensão suíços (HENNEBERRY \& ROBERTS, 2008 apud VAN LOON \& AALBERS, 2017). Esse trabalho tem por objetivo, portanto, compreender o papel dos fundos de pensão na produção do espaço urbano através de uma análise da sua atuação no mercado imobiliário comercial - para tanto, analisa-se o que a literatura internacional recente tem apontado com relação às novas práticas profissionais de gestão imobiliária adotadas e os impactos que essas geram no meio ambiente urbano construído. Conforme investigado por Theurillat et al. (2010), ambas as formas de investimento no mercado imobiliário, a direta (através da compra de imóveis) e indireta (através da compra de veículos financeiros), dos fundos de pensão suíços, resultaram em diversificação espacial limitada em certas áreas, urbanas e metropolitanas, e certos tipos de segmentos, residencial e comercial. Os fundos de pensão estariam, portanto, "construindo geografia" (LEE, 2002 apud SANFELICI \& HALBERT, 2018) na medida em que "selecionam usos, usuários e condições de acesso a elementos do ambiente urbano construído" (THEURILLAT et al., 2010; VAN LOON \& AALBERS, 2017).

Les fonds de pension sont des acteurs importants dans les économies mondiales. La financiarisation a modifié la manière dont les investisseurs institutionnels gèrent leurs fonds propres, ainsi que leur façon de mesurer et de voir les résultats et objectifs (SAUVIAT, 2005). La littérature récente indique que ces changements dans la rationalité des fonds de pension résultant à des stratégies de placement différenciées, y compris des investissements immobiliers. Comme le souligne Van Loon \& Aalbers (2017), il existe actuellement peu de connaissances sur la manière dont les objectifs financiers ont fini par dominer et modifier les stratégies de placement des investisseurs institutionnels et leur incidence sur l'espace urbain construit. En fait, la seule recherche qui ait réellement montré comment et pourquoi ces stratégies produisaient des effets particuliers sur la ville était celle développée par Theurillat et al. (2010) pour le cas des fonds de pension suisses (HENNEBERRY \& ROBERTS, 2008 apud VAN LOON \& AALBERS, 2017). Cet article vise donc à comprendre le rôle des fonds de pension dans la production d'espaces urbains à travers une analyse de leurs performances sur le marché de l'immobilier commercial - à cette fin, nous analysons ce que la littérature internationale récente a souligné concernant les nouvelles pratiques professionnelles de gestion de l'immobilier adoptées et leurs impacts sur l'environnement urbain construit. Comme étudié par Theurillat et al. (2010), les deux formes d'investissement immobilier, directe (via l'achat immobilier) et indirecte (via l'achat de véhicules financiers), des fonds de pension suisses, ont abouti à une diversification spatiale limitée de certaines zones, urbaines et urbaines, zones métropolitaines et certains types de segments, résidentiels et commerciaux. Les fonds de pension seraient donc «géographiquement construits» (LEE, 2002 apud SANFELICI \& HALBERT, 2018) puisqu'ils «choisiraient les utilisations, les utilisateurs et les conditions d'accès aux éléments de l'environnement urbain construit» (THEURILLAT et al., 2010). ; VAN LOON \& AALBERS, 2017).

Los fondos de pensiones se clasifican como importantes agentes en las economías mundiales. La financierización alteró la forma en que los inversores institucionales realizan la gestión de su patrimonio y también la forma en que miden y ven resultados y metas (SAUVIAT, 2005). La literatura reciente apunta que esos cambios en la racionalidad de los fondos de pensión resultaron en estrategias de inversión diferenciadas, incluso en lo que concierne a la inversión en 
bienes inmuebles. Como señalan Van Loon \& Aalbers (2017), actualmente hay poco conocimiento producido sobre cómo los objetivos financieros han venido a dominar y modificar las estrategias de inversión de los inversores institucionales y cómo esto afecta al espacio urbano construido -en realidad, la única investigación que de hecho mostró cómo y por qué estas estrategias producen ciertos efectos en la ciudad, fue la desarrollada por Theurillat et al. (2010) para el caso de los fondos de pensiones suizos (HENNEBERRY \& ROBERTS, 2008 apud VAN LOON \& AALBERS, 2017). Este trabajo tiene por objetivo, por lo tanto, comprender el papel de los fondos de pensiones en la producción del espacio urbano a través de un análisis de su actuación en el mercado inmobiliario comercial - para tanto, se analiza lo que la literatura internacional reciente ha señalado con relación a las nuevas prácticas profesionales de gestión inmobiliaria adoptadas y los impactos que estas generan en el medio ambiente urbano construido. Según lo investigado por Theurillat et al. (2010), ambas formas de inversión en el mercado inmobiliario, la directa (a través de la compra de inmuebles) e indirecta (a través de la compra de vehículos financieros), de los fondos de pensiones suizos, resultaron en diversificación espacial limitada en ciertas áreas, urbanas y urbanas metropolitanas, y ciertos tipos de segmentos, residencial y comercial. Los fondos de pensiones estarían, por lo tanto, "construyendo geografía" (LEE, 2002 apud SANFELICI \& HALBERT, 2018) en la medida en que "seleccionan usos, usuarios y condiciones de acceso a elementos del ambiente urbano construido" (THEURILLAT et al., 2010) , VAN LOON \& AALBERS, 2017).

Pension funds are important players in world economies. Financialization has altered the way in which institutional investors manage their assets and also how they measure and see results and goals (SAUVIAT, 2005). Recent literature suggests that these changes in the rationality of pension funds have resulted in differentiated investment strategies, including investment in real estate. As Van Loon \& Aalbers (2017) point out, there is little actual knowledge about how financial goals have come to dominate and change the investment strategies of institutional investors and how this affects built urban space - in effect, the only research that in fact showed how and why these strategies produce certain effects in the city, was developed by Theurillat et al. (2010) for the case of Swiss pension funds (HENNEBERRY \& ROBERTS, 2008 apud VAN LOON \& AALBERS, 2017). The purpose of this paper is to understand the role of pension funds in the production of urban space through an analysis of their performance in the commercial real estate market - therefore, it is analyzed what the recent international literature has pointed out regarding the new professional practices of real estate management adopted and the impacts that these generate in the built urban environment. As investigated by Theurillat et al. (2010), both forms of real estate investment, direct (through the purchase of real estate) and indirect (through the purchase of financial vehicles) of Swiss pension funds, resulted in limited spatial diversification in certain areas, urban and metropolitan, and certain types of segments, residential and commercial. Pension funds were thus "building geography" (LEE, 2002 apud SANFELICI \& HALBERT, 2018) in that they "select uses, users and conditions of access to elements of the built urban environment" (THEURILLAT et al., 2010 ; VAN LOON \& AALBERS, 2017).

\section{ÍNDICE}

Mots-clés: fonds de pension, marché immobilier, financiarisation.

Palavras-chave: Fundos de pensão, mercado imobiliário, financeirização.

Keywords: Pension funds, real estate, financialization.

Palabras claves: Fondos de pensiones, mercado inmobiliario, financierización. 
AUTOR

MAIRA MAGNANI ASENCIO

Universidade Federal Fluminense (UFF). Departamento de Geografia. Mestranda. E-mail: mairamagnani@uol.com.br 